\title{
Optimization of cashew (Anacardium occidentale L.) apple juice's clarification process by using cassava and rice starch
}

Emmanuelle S.C.A. Dedehou', Joseph Dossou¹, Bonaventure Ahohuendo¹, Aliou Saidou', Adam Ahanchede ${ }^{1}$, Mohamed M. Soumanou ${ }^{2 *}$

${ }^{1}$ Faculté des Sciences Agronomiques, Université d'Abomey-Calavi, B.P. 526 Cotonou, Bénin 2Ecole Polytechnique d'Abomey-Calavi, Université d'Abomey-Calavi, 01 B.P. 2009, Cotonou, Bénin

"Correspondent author address: Mohamed M. Soumanou, msoumanoufr@yahoo.fr

Original submitted in on $6^{\text {th }}$ October 2015. Published online at www.m.elewa.org on $30^{\text {th }}$ November 2015 http://dx.doi.org/10.4314/jab.v95i1.9

\begin{abstract}
Objective: This study aims to optimize cashew apple juice clarification by using cassava and rice starch. Materiel and methods: Effects of dose of cassava and rice starch, incubation time at $30^{\circ} \mathrm{C}$ on clarity of cashew apple juice were investigated. Parameters such as, tannins, phenols, colour, vitamin $C$ contents of cashew apple juice were evaluated using response surface methodology (RSM) and the optimum condition for cashew apples juice clarification by using cassava and rice starch was determined.

Results: The regressions analysis showed that cassava starch dose and clarification time significantly $(P<0.001)$ influence juice clarity, while only clarification time significantly $(p<0.05)$ influence juice clarity with rice starch. The increase of cassava starch and rice starch dose significantly $(p<0.05)$ decreases the tannins content. Cassava starch at $6.2 \mathrm{ml} / \mathrm{l}$ for 300 minutes decreased tannins content at $34.2 \%$ with visual clarity of $93.75 \%$, while rice starch at $10 \mathrm{ml} / \mathrm{l}$ for 193 minutes decreased tannins content at $42.14 \%$ with visual clarity of $94.8 \%$.

Conclusion: cassava and rice starch behaviour during cashew apples juice clarification were not similar. Nevertheless, from the results of optimization, cassava and rice starch preparations appeared efficient clarifying agents for cashew apple juice. The use of these efficient and economic natural local clarifying agents could improve the valorization of cashew products in developing countries.

Keywords: Cashew, clarification, starch, optimization, Response Surface Methodology.
\end{abstract}

\section{INTRODUCTION}

Cashew apple (figure 1) is the edible portion (pseudo fruit) of the cashew fruit, representing $90 \%$ of its weight. It is consumed as a fresh fruit. It has rich flavour and aroma, and vitamin $\mathrm{C}$ content, being an adequate raw material for juices, exotic beverages and other products (Paiva et al., 2000). Besides possessing nutritional properties, these are not consumed like other fruits due to astringency. Astringency is due to the presence of tannins $(0.35 \%)$ (Michodjehoun-Mestres et al., 2009). The production process of fruit and vegetable juices includes steps like extraction, clarification, and stabilization (Bhat, 2000). Fruit juices are naturally cloudy, yet in different degrees, especially due to presence of polysaccharides (pectin, cellulose, hemicelluloses, lignin and starch), proteins, tannins and metals (Vaillant et al., 2001). The clarification of cashew apple juice 


\section{Dedehou et al. J. Appl. Biosci. Optimization of cashew (Anacardium occidentale L.) apple juice's}

clarification process by using cassava and rice starch

by removing astringency is an important step in cashew apple processing. Indeed clarification is a process by which the semi-stable emulsion of colloidal plant carbohydrates that support the insoluble cloud material of a freshly pressed juice is "broken". It can be accomplished enzymatically and non-enzymatically (Kilara \& Van Buren, 1989). Fining, or clarifying, agents are grouped according to their general nature in (1) Earths (bentonite, kaolin); (2) Proteins (gelatine, isinglass, casein, albumen); (3) Polysaccharides (agars); (4) Carbons; (5) Synthetic polymers (PVPP, nylon); (6) Silicon dioxide (kieselsols); and (7) Others, including metal chelators, enzymes (Zoecklein, 1988). Many clarifying agents recommended such as 'sago' (a refined commercial preparation of starch from cassava (Manihot esculenta), starch, gelatine and poly vinyl pyrolidone (PVP) were used for cashew apple juice clarification (Jayalekshmy \& John, 2004). According to these authors, the mechanism of separation of tannin from the cashew apple juice is different for different clarifiers. Most of the methods used to remove tannins from cashew apple are costly and several clarification agents have to be imported into developing countries. In order to improve the valorization of cashew products in developing countries such as Benin it is necessary to find an efficient and economic natural clarifying agent to remove cashew apple tannin. Dèdéhou et al. (2015) identified in Benin two processes of cashew apple juice production: the process of natural cashew apple juice production and the process of cajuina production. These authors showed that whatever the process used, the fruits are selected, washed, cut out and pressed. The juice obtained is then clarified by addition of a clarifying agent like cassava starch or rice gruel, and then filtered before any heat treatment. The major constraints recorded in the production of the cashew apple juice in Benin, is the non control by the producers of the time and the dose of the clarifying agent, which are necessary for the good elimination of the tannins, the dilution of the juice induced by the rice gruel added to the raw juice for the clarification (Dèdéhou et al., 2015). Optimization of the process conditions is one of the most critical stages in the development of an efficient and economic bioprocess. This study aims to investigate the optimization of cashew apple juice clarification process by using cassava and rice starch by response surface methodology (RSM).

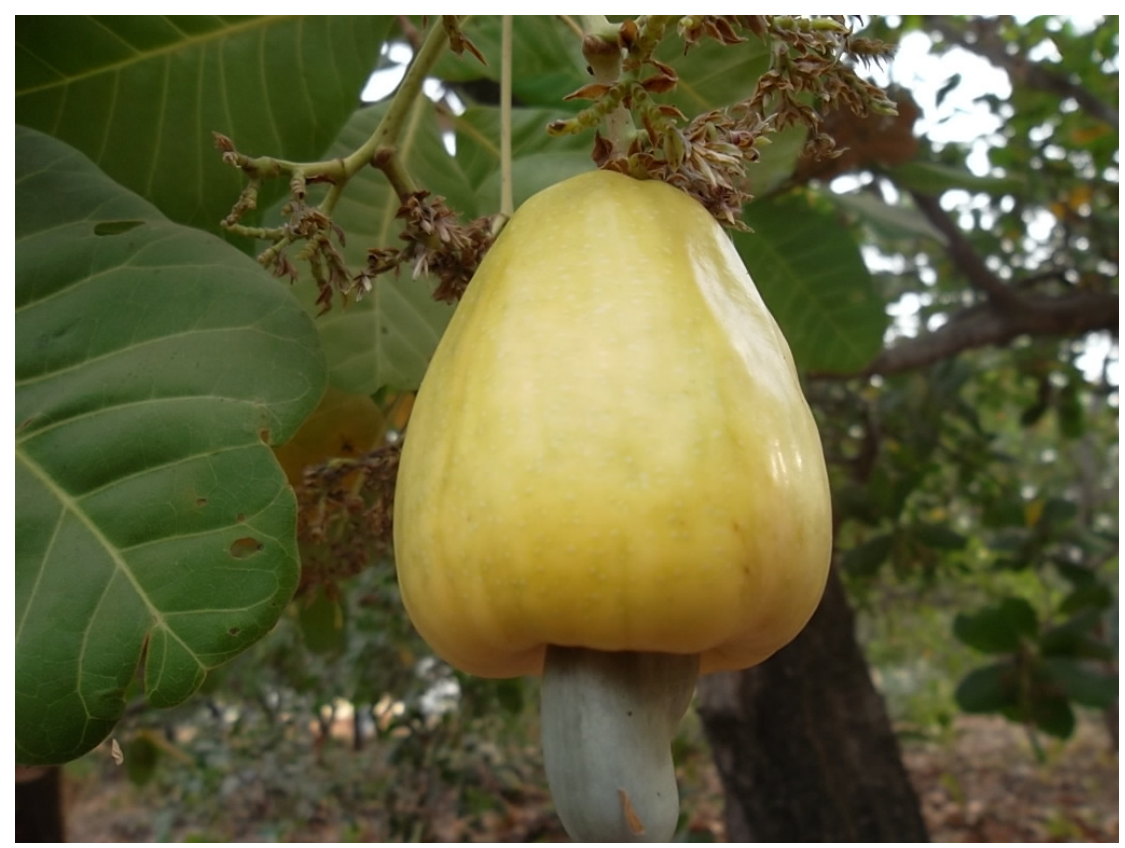

Figure 1: Cashew nut (1) and Cashew apple (2) 


\section{MATERIALS AND METHODS}

Materials: The vegetable material used constituted ofRipe cashew apples gathered from Bantè $\left(8^{\circ} 25^{\prime} 0^{\prime \prime} \mathrm{N}\right.$ and $\left.1^{\circ} 52^{\prime} 60 " \mathrm{E}\right)$, one locality of high production of the cashew tree in Benin. The apples were sent at the laboratory in the University of Abomey-Calavi under refrigeration conditions.

- Based on preliminary experiments, the variety of rice Nerica 1 and the variety of cassava RB89509 were used for this study. Indeed, starches of five varieties of manioc: OKOYAWO, BEN86052, RB89509, TMS30572 and 92B/00068 and of five varieties of rice WAB 638-1, TOX 56-81, NERICA 1, IR 841, and Special rice, were tested for cashew apple juice clarification. The starches of RB 89509 and NERICA 1 gave volumes of sediment most significant after 3 hours of pause. Nerica or New Rice Cultivar for Africa was obtained following interspecific crossings intended to combine the good productivity of Asian rice (O. sativa) and the rusticity of African rice (0. glaberrima) (ADRAO, 2003). It presents high outputs of more than $4.5 \mathrm{~T} / \mathrm{ha}$ and a short cycle of maturation (90 to 100 days) and is in full diffusion in Benin account of its agronomic characteristics. RB89509 is an improved cassava variety vulgarized at $88 \%$ in Benin (Glèlè et al., 2008) and including in the lot of resistant varieties to parasitic attacks with short developments cycle introduced in rural environment by National Institute of Agricultural Research of Benin (INRAB) and International Institute of Tropical Agriculture (IITA) with a high output of 29 T/ha (Zoffoun et al., 2001). RB89509 and Nerica 1 were given by INRAB.

\section{Methods}

Juice extraction: The collected cashew fruits were transported to the laboratory, where the nuts were detached. The apples were washed thoroughly with distilled water. Then, they were cut and the juice obtained by pressing the mash through a muslin cloth was used for various clarification assays.

Extraction processes of cassava and rice starches: The extraction process of cassava and rice starches is respectively summarized in the diagrams of figures 1 and 2. 


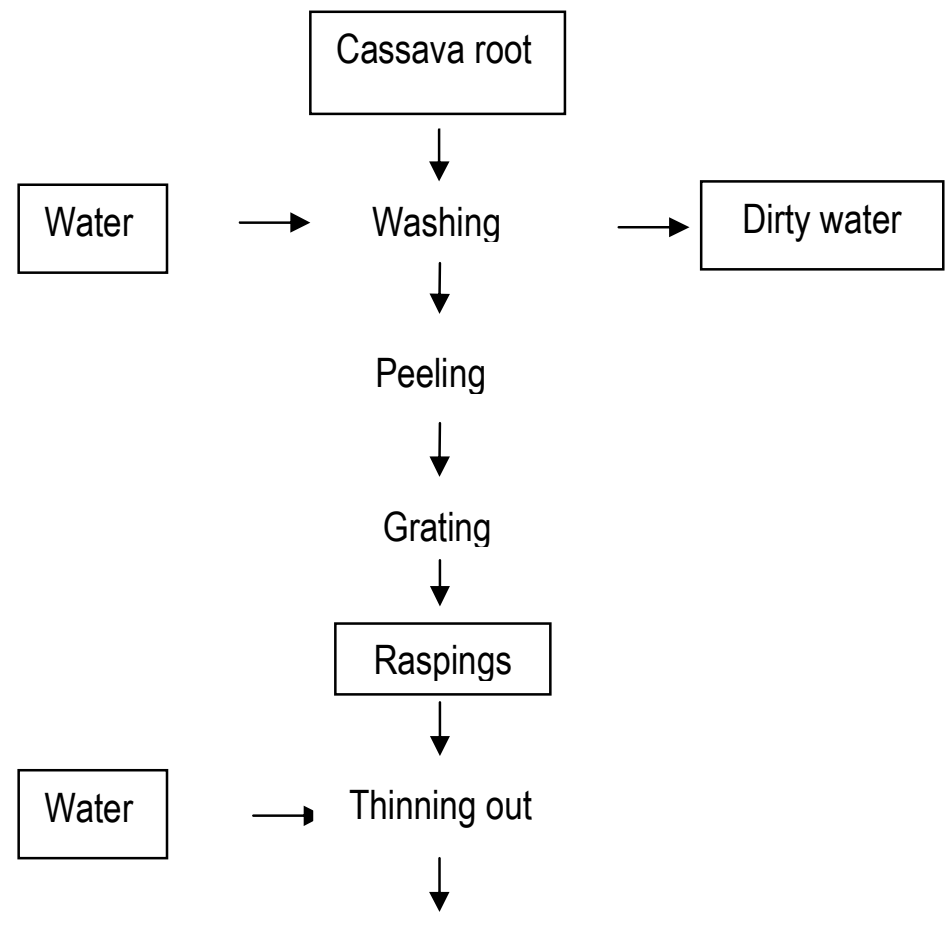

Filtration

(throuah muslin cloth)


Figure 1: Production diagram of cassava starch 


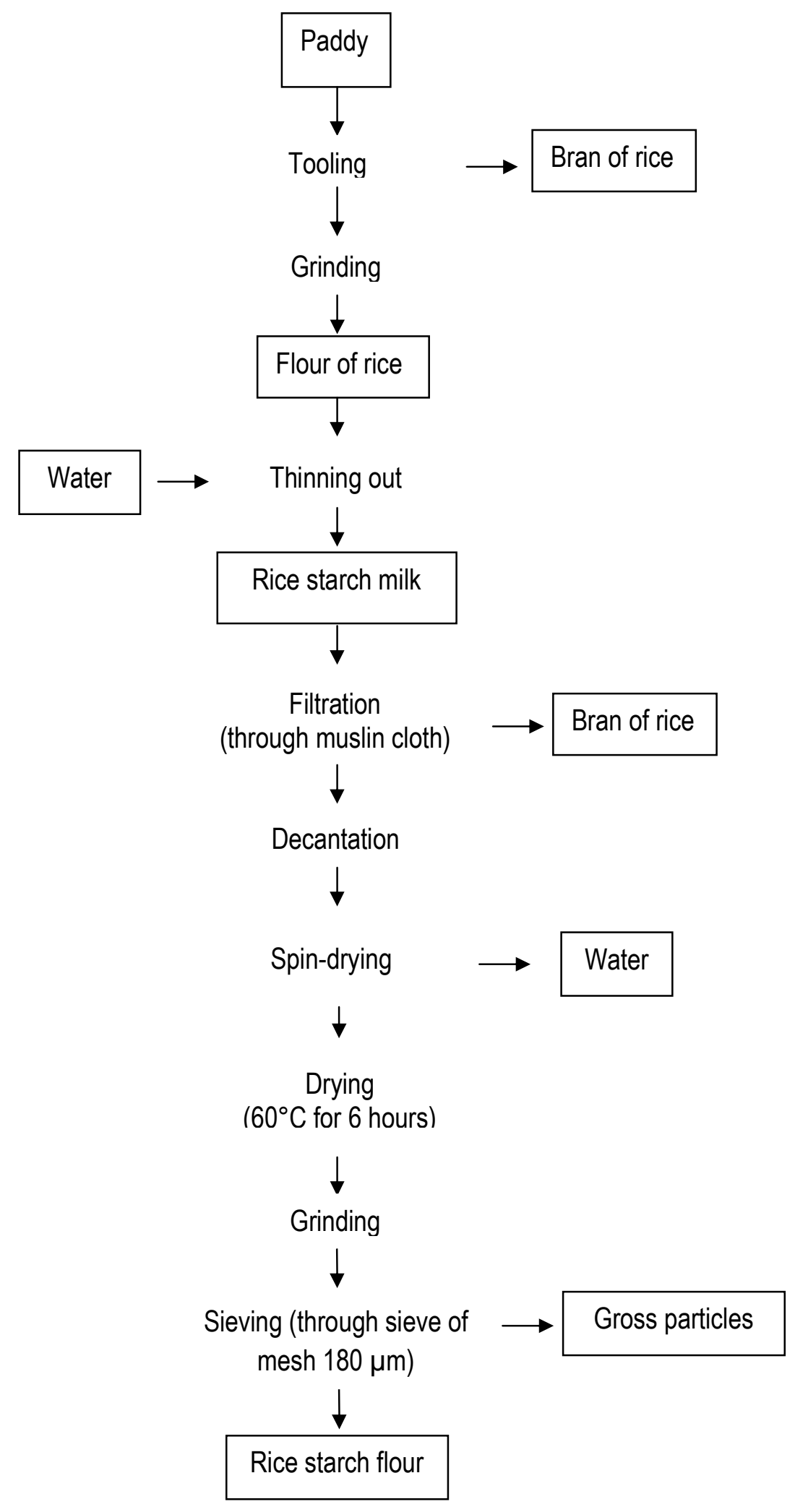

Figure 2: Production diagram of rice starch 


\section{Dedehou et al. J. Appl. Biosci. Optimization of cashew (Anacardium occidentale L.) apple juice's clarification process by using cassava and rice starch}

The pysicochemical characteristics of cassava and rice starches used were presented in the table 1.

Table 1: Physicochemical characteristics of cassava and rice starch used ${ }^{*}$

\begin{tabular}{|c|c|c|c|c|c|c|}
\hline \multirow[b]{2}{*}{ Starch } & \multicolumn{6}{|c|}{ Parameters } \\
\hline & $\mathrm{pH}$ & $\begin{array}{l}\text { Acidity } \\
(\%)\end{array}$ & $\begin{array}{l}\text { Humidity } \\
(\%)\end{array}$ & $\begin{array}{l}\text { Protein } \\
(\%)\end{array}$ & $\begin{array}{l}\text { Amylose } \\
(\%)\end{array}$ & $\begin{array}{l}\text { Amylopectin } \\
(\%)\end{array}$ \\
\hline Cassava (RB 89509) & 4.2 & 5.5 & 10.52 & 0.3 & 21 & 79 \\
\hline Rice (Nerica1) & 3.9 & 7.0 & 10.78 & 0.2 & 24 & 76 \\
\hline
\end{tabular}

${ }^{*}$ Authors' unpublished work

Experimental design and Statistical analysis: RSM was applied in order to determine the optimum conditions for clarification of cashew apple juice by using cassava and rice starch. As shown in Table 2, the experimental design for processing conditions was based on a central composite design. Independent variables such as dose $\left(X_{1}: 1-10 \mathrm{ml} / \mathrm{l}\right)$, and incubation time $\left(X_{2}: 30-300 \mathrm{~min}\right)$, were assigned as numbers $(-1$, 0 , 1). The total number of experiments was 13 , including 9 at factorial points and 4 replications at the centre point (11). The dependent variables $(Y n)$, such as clarity $(\mathrm{Y} 1)$, tannin content $(\mathrm{Y} 2)$, phenol content $(\mathrm{Y} 3)$, colours (Y4) and vitamin C content (Y5) were calculated 3 times and their average values were used for regression analysis. All statistical analyses were carried out by employing the statistical package Minitab 14 (Minitab Inc., USA). The fitted polynomial equations were expressed in 3D response surface graphs, in which the response is presented on the vertical axis and two factors at the two horizontal perpendicular axes. The analysis of variance (ANOVA) was used to determine significant differences between independent variables $(p<0.05)$.

Table 2: The central composite experimental design matrix (coded and real values for independent variable levels) for cashew apple juice clarification by using cassava and rice's starch

\begin{tabular}{ccccc}
\hline \multicolumn{2}{c}{ Codes } & \multicolumn{3}{c}{ Factors } \\
\hline $\mathrm{N}^{\circ}$ & Dose of starch $(\mathrm{ml} / \mathrm{l})$ & Time $(\mathrm{min})$ & Dose of starch $(\mathrm{ml} / \mathrm{l})$ & Time $(\mathrm{min})$ \\
\hline 1 & +1 & +1 & 10 & 300 \\
2 & -1 & +1 & 1 & 300 \\
3 & 0 & +1 & 5.5 & 300 \\
4 & +1 & -1 & 10 & 30 \\
5 & +1 & 0 & 10 & 165 \\
6 & 0 & 0 & 5.5 & 165 \\
7 & 0 & 0 & 5.5 & 165 \\
8 & 0 & 0 & 5.5 & 165 \\
9 & 0 & 0 & 5.5 & 165 \\
10 & 0 & +1 & 5.5 & 30 \\
11 & 0 & -1 & 5.5 & 165 \\
12 & -1 & 0 & 1 & 165 \\
13 & -1 & -1 & 1 & 30 \\
\hline
\end{tabular}

Experimental clarification of the cashew apple juice: The starch solutions used are obtained by dissolution of $5 \%(\mathrm{p} / \mathrm{v})$ of either cassava starch powder or rice starch powder in water at $60^{\circ}$ C.For each test, $200 \mathrm{ml}$ of raw cashew apple juice were treated under the conditions indicated by the model. Filtrate recovered by filtration through Whatman paper $\mathrm{N}^{\circ} 1$ was used for the various physicochemical analyses.
Optimization of the parameters of clarification : To determine the conditions allowing an optimal clarification of cashew apples juice by using cassava and rice starch, the function of desirability was used to optimize the starch dose and clarification time. The target values of the clarified juices with cassava and rice starch were selected to minimize the tannin content and to maximize the clarity. Indeed, according to 
Talasila et al. (2012) the clarification by the various agents modifies only clarity and astringency due to the tannin. To check the adequacy of the model, two experiments (one with cassava starch and the other with the rice starch) by using the optimal values of the starch dose and the clarification times predicted by the model were done.

Physico-chemical analysis: Total phenolic content in the cashew apple juice was determined using the protocol of Folin-Ciocalteu (FC) reagent in colorimetric

\section{RESULTS AND DISCUSSION}

The data of the model for the optimization and physicochemical characteristics of cashew apple juice clarified by using the starch of cassava and rice are presented in table 3. The analysis of the physicochemical composition of the clarified juices with the cassava's starch reveals that the contents of tannin, vitamin $\mathrm{C}$ and phenol vary respectively from 65.78 to $160.82 \mathrm{mg} \mathrm{Eq}$ Catechin/100ml; 284.46 to 457.71 $\mathrm{mg} / 100 \mathrm{ml}$ and 2107.5 to $3478.8 \mathrm{~g} / \mathrm{l}$. The clarity and the analysis as described by Kayodé et al. (2006).The content of condensed tannins was determined by the method of vanillin and was expressed as the equivalent of catechin according to Broadhurst \& Jones (1978). Vitamin $C$ was determined by titration with the iodine (AOAC, 2000). Clarity and the colour were measured with spectrophotometer UV (JENWAY 6715 UV/Vis. Spectrophotometer) with the respective wavelengths of $660 \mathrm{~nm}, 420 \mathrm{~nm}$. Distilled water was used as control.

colour vary from 64.7 to $98.0(\% \mathrm{~T})$ and from 0.182 to 0.294 (Asb).While the analysis of the physicochemical composition of the clarified juices with the rice's starch reveals that the contents of tannin, vitamin $\mathrm{C}$ and phenol vary respectively from 54.56 to $179.08 \mathrm{mg} \mathrm{Eq}$ Catechin/100ml; 303.60 to $417.12 \mathrm{mg} / 100 \mathrm{ml} ; 1798.8$ to $3051.3 \mathrm{~g} / \mathrm{l}$. The clarity and the colour vary from 74.4 to $98.1(\% \mathrm{~T})$ and from 0.151 to 0.359 (Asb).

Table 3: Physicochemical characteristics of cashew apple juice samples clarified using cassava (M) and rice (R) starch.

\begin{tabular}{llllll}
\hline Code & $\begin{array}{l}\text { Clarity M/R (\% of } \\
\text { Transmittance) }\end{array}$ & $\begin{array}{l}\text { Colour M/R } \\
\text { (Abs) }\end{array}$ & $\begin{array}{l}\text { Tannin M/R }(\mathbf{m g ~ E q} \\
\text { Catechin/100ml) }\end{array}$ & $\begin{array}{l}\text { Vitamin C M/R } \\
\text { (mg/100ml) }\end{array}$ & $\begin{array}{l}\text { Phenol M/R (mg } \\
\text { Ac gali/L) }\end{array}$ \\
\hline 1 & $91.0 / 95.7$ & $0.226 / 0.216$ & $65.78 / 99.88$ & $284.46 / 364.98$ & $2107.5 / 1798.8$ \\
2 & $98.0 / 95.9$ & $0.218 / 0.228$ & $133.76 / 179.08$ & $388.74 / 417.12$ & $3171.3 / 2517.5$ \\
3 & $94.2 / 95.7$ & $0.214 / 0.216$ & $67.98 / 117.04$ & $441.87 / 380.82$ & $2245.0 / 2760.0$ \\
4 & $64.7 / 74.4$ & $0.294 / 0.313$ & $65.78 / 95.92$ & $379.50 / 331.32$ & $2731.3 / 2075.0$ \\
5 & $81.3 / 98.6$ & $0.224 / 0.151$ & $83.16 / 54.56$ & $402.93 / 307.23$ & $2390.0 / 186.00$ \\
6 & $87.9 / 92.3$ & $0.230 / 0.223$ & $67.54 / 86.24$ & $453.75 / 382.14$ & $2258.8 / 2455.0$ \\
7 & $85.0 / 93.3$ & $0.195 / 0.231$ & $71.28 / 89.54$ & $357.06 / 398.31$ & $2570.0 / 2378.8$ \\
8 & $88.4 / 87.9$ & $0.228 / 0.300$ & $75.46 / 100.98$ & $290.40 / 363.33$ & $2715.0 / 2790.0$ \\
9 & $87.8 / 88.1$ & $0.239 / 0.284$ & $75.02 / 100.32$ & $307.56 / 363.66$ & $2236.3 / 2350.0$ \\
10 & $77.9 / 77.7$ & $0.240 / 0.313$ & $104.72 / 71.28$ & $302.61 / 368.28$ & $2258.8 / 2190.0$ \\
11 & $90.1 / 83.3$ & $0.282 / 0.359$ & $93.28 / 111.1$ & $408.54 / 318.78$ & $2592.5 / 2896.3$ \\
12 & $98.0 / 98.1$ & $0.202 / 0.193$ & $143 / 160.82$ & $457.71 / 303.60$ & $2207.5 / 3051.3$ \\
13 & $98.0 / 97.5$ & $0.182 / 0.174$ & $160.82 / 107.8$ & $407.88 / 416.79$ & $3478.8 / 2392.5$ \\
\hline Control & 98 & & 193 & & \\
\hline
\end{tabular}

Codes 1 to 13 represent the values of factors for the model (1=dose:10 ml/time $300 \mathrm{~min}$; 2= dose: $1 \mathrm{ml} / \mathrm{time} 300 \mathrm{~min}$; 3=dose: $5.5 \mathrm{ml} /$ time $300 \mathrm{~min}$;=dose: $10 \mathrm{ml} / \mathrm{time} 30 \mathrm{~min}$; 5=dose: $10 \mathrm{ml} / \mathrm{time} 165 \mathrm{~min} ; 6-9,11=$ dose:5.5ml/time 165 min; 10= dose:5.5 ml/time 30 min;12 = dose:1 m//time $165 \mathrm{~min} ; 13$ = dose: $1 \mathrm{ml} / \mathrm{time} 30 \mathrm{~min}$

$Y M_{1}=87.83-9.5^{\star * *} X_{1}+7.1^{* * *} X_{2}+1.8 X_{1}^{2}-1.7 X_{2}^{2}+6.6^{* * *} X_{1} X_{2}(E q 1) .\left(R^{2}=98.0 \%\right)$

Eq. (1) shows that the decrease in cassava starch dose and the increase of clarification time significantly $(\mathrm{P}<0.001)$ increase the clarity response $\left(\mathrm{YM}_{1}\right)$. Only the linear effects of cassava starch dose and the clarification time have a significant $(p<0.05)$ influence on clarity. The interaction effect between clarification time and cassava starch dose was significant $(p<0.001)$ and its effect were positive on juice clarity. $98.0 \%$ of the 


\section{Dedehou et al. J. Appl. Biosci. Optimization of cashew (Anacardium occidentale L.) apple juice's clarification process by using cassava and rice starch}

clarity variations are due to cassava starch dose and the clarification time. The Fig. 3a shows the interaction effect between cassava starch dose and clarification time on juice clarity.

$Y R_{1}=89.7-3.8 X_{1}+6.3^{*} X_{2}+6.9^{*} X_{1}{ }^{2}-4.8 X_{2}{ }^{2}+5.7^{*} X_{1} X_{2}(E q 2) .\left(R^{2}=79.6 \%\right)$

Numerical coefficients in Eq. (2) reveals that the increase of clarification time significantly $(p<0.05)$ increase the clarity response $\left(\mathrm{YR}_{1}\right)$ while rice starch dose $(X 1)$ do not influence this response at $p<0.05$. Clarification time significantly $(p<0.05)$ had a positive effect on juice clarity at linear and quadratic level. The interaction effect between clarification time and rice starch dose was significant $(p<0.05)$ and its effect were positive on juice clarity. The Fig. $3 b$ shows the interaction effect between rice starch dose and clarification time on juice clarity. Fining agents work by sticking to the particles, or by using charged ions to cause particles to stick to each other, in any case making them heavy enough to sink to the bottom by the action of gravity to modify clarity (Benitez \& Lozano, 2007). Clarification of in natura cashew pulp and hydrolyzed pulp using the processes of microfiltration and ultrafiltration increase the luminosity of the clarified juice (Castro et al., 2007). In the case of enzymatic clarification, enzyme concentration is the most important factor influencing clarification. For example, the increasing in polygalacturonase concentration increased the clarity of apple juice by exposing part of the positively charged protein beneath, thus reducing electrostatic repulsion between cloud particles which cause these particles to aggregate to larger particles and eventually settle out (Dey \& Rintu Banerjee, 2014). For those authors, decolorized and partially purified enzymes improved the clarity of the juice as well as reduced the amount of some of the haze active phenolics, but a high clarity is rare without ultrafiltration and fining agent like gelatin/bentonite.

$Y_{2} M=78.8-37.1^{* * *} X_{1}-10.6 X_{2}+28.6^{* *} X_{1}{ }^{2}+1.9 X_{2}{ }^{2}+6.8 X_{1} X_{2}(E q)$ ). $\left(R^{2}=92.9 \%\right)$

According to Eq. (3), the increase of cassava starch dose significantly $(p<0.001)$ decrease the tannin response $\left(Y_{2} M\right)$. While clarification time $\left(X_{2}\right)$ do not influence this response at $p<0.05$. Only cassava starch dose had a positive effect on juice tannin content at linear and quadratic level. The fig. 4 a shows the interaction effect between cassava starch dose and clarification time on juice tannin content.

$$
\left.Y_{2} R=95.4-32.9^{* *} X_{1}+20.2^{*} X_{2}+18 X_{1}{ }^{2}+4.5 X_{2}^{2}-16.8 X_{1} X_{2} \text { (Eq 4). ( } R^{2}=86.1 \%\right)
$$

Eq. (4) indicates that increasing of rice starch dose and the decreasing of clarification time significantly $(P<0.05)$ decrease the tannin content response $\left(Y_{2} R\right)$. Only the linear effects of rice starch dose and clarification time were significant. The fig. $4 \mathrm{~b}$ shows the interaction effect between rice starch dose and clarification time on juice tannin content. Many studies showed that clarification processes gave reduction of condensed tannins (Castro et al., 2007). Abreu et al. (2005) had observed also reduction of condensed tannins in clarified cashew apple juice with ceramic membranes. Talasila et al. (2012) study reveals that sago at a concentration of $2 \mathrm{~g} / \mathrm{L}$ was efficient in decreasing tannins. The decrease could be due to the formation of insoluble tannin-starch complexes, which are precipitated and filtered later such as in the case of tannin precipitation by protein (Hagerman \& Butler, 1978). On the other hand, Talasila et al. (2012) observed that low concentration of sago $(2 \mathrm{~g} / \mathrm{L})$ was efficient in decreasing tannins than higher concentrations (4 g/L) as less hydroxyl groups are available for precipitation due to the formation of soluble complexes. Sago was effective in decreasing tannin content at lower concentrations whereas gelatine and PVP at higher concentrations. Gelatin at a concentration of $4 \mathrm{~g} / \mathrm{L}$ decreased tannins by 37.36 and $36.26 \%$, PVP at a concentration of $4 \mathrm{~g} / \mathrm{L}$ decreased tannins by $31.86 \%$. PVP at lower concentrations ( $2 \mathrm{~g} / \mathrm{L})$ and starch at concentrations (2 and $4 \mathrm{~g} / \mathrm{L}$ ) were not effective in decreasing tannins (Talasila et al., 2012). At low gelatin/PVP/starch concentrations, the numbers of sites available for interaction with tannins are less in number, resulting in weak hydrogen bonding between the phenolic hydroxyl groups of the tannins and the carbonyl groups of the chemical/protein (Van Buren, 1969). 
$\mathrm{Y}_{3} \mathrm{M}=2364.7-271.5 \mathrm{X}_{1}-157.5 \mathrm{X}_{2}+208.5 \mathrm{X}^{2}+161.7 \mathrm{X}_{2}^{2}-79.1 \mathrm{X}_{1} \mathrm{X}_{2}(\mathrm{Eq} 5) .\left(\mathrm{R}^{2}=46.0 \%\right)$

$Y_{3} R=2596.2-371.2^{*} X_{1}+69.8 X_{2}-195.9 X_{1}{ }^{2}-176.6 X_{2}{ }^{2}-100.3 X_{1} X_{2}(E q 6) .\left(R^{2}=68.3 \%\right)$

$Y_{4} M=0.2+0.0 X_{1}-0.0 X_{2}-0.0 X_{1}^{2}+0.0 X_{2}^{2}-0.0 X_{1} X_{2}(E q 7) .\left(R^{2}=58.8 \%\right)$

$Y_{4} R=0.3+0.0 X_{1}-0.0 X_{2}-0.0 X_{1}^{2}+0.0 X_{2}^{2}-0.0 X_{1} X_{2}(E q)$ 8). $\left(R^{2}=52.5 \%\right)$

$Y_{5} M=373.6-31.2 X_{1}+4.2 X_{2+} 31.1 X_{1}^{2}-26.9 X_{2}^{2}-19 X_{1} X_{2}(E q 9) .\left(R^{2}=23.4 \%\right)$

$Y_{5} R=355.9-22.3 X_{1}+7.7 X_{2}-27.1 X_{1}^{2}+42.0 X_{2}^{2}+X_{1} X_{2}(E q 10) .\left(R^{2}=51.3 \%\right)$

With: $X_{1}$ and $X_{2}$ : linear effect of cassava starch dose and the time of clarification respectively; $X_{12}$ and $X_{22}$ : quadratic effect of cassava starch dose and the time of clarification respectively; $X_{1} X_{2}$ : interactive effect; ${ }^{*}=$ significant $(P<0$. $05) ;{ }^{* *}=$ highly significant $(P<0,01) ;{ }^{* *}=$ Very highly significant $(P<0,001) \cdot R 2=$ coefficient of determination adjusted

Equations (5) to (10) show the regression obtained for phenol $\left(Y_{3}\right)$ colour $\left(Y_{4}\right)$ and vitamin $C\left(Y_{5}\right)$ responses, respectively, in relation to the significant variables and to the interaction between them at $p<0.05$. The linear and quadratic effects of cassava starch dose nor rice starch dose and clarification time do not have globally any significant influence $(P<0.05)$ on the colour, vitamin $\mathrm{C}$ and phenol of the juices.

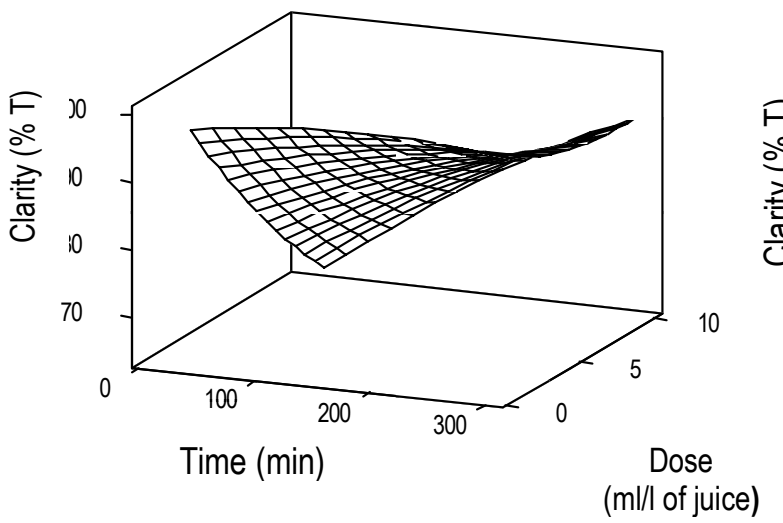

(a) Cassava starch

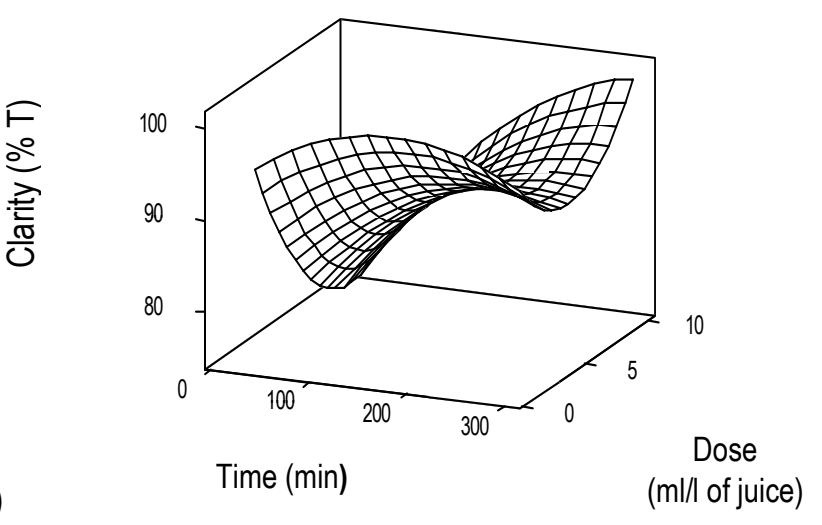

(b) Rice starch

Figure 3: Response surface plots (3D) depicting the effects of starch dose and clarification time on clarity of cashew apple juice.

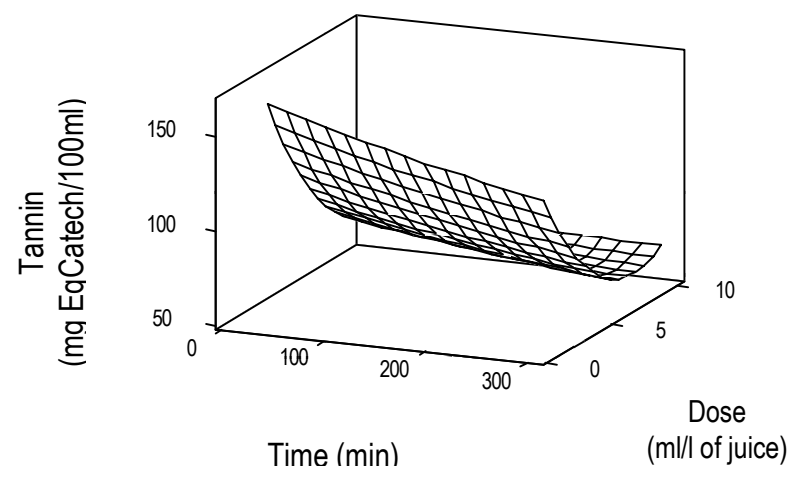

(a) Cassava starch

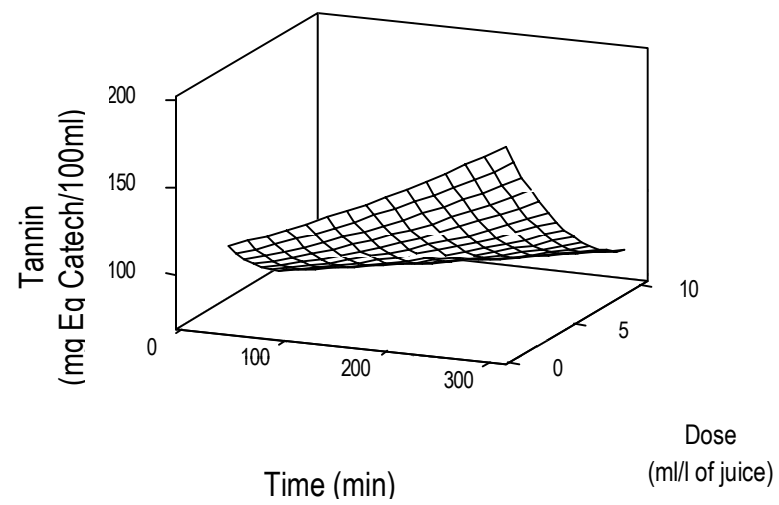

(b) Rice starch

Figure 4: Response surface plots (3D) depicting the effects of starch dose and clarification time on tannin content of cashew apple juice. 


\section{Dedehou et al. J. Appl. Biosci. Optimization of cashew (Anacardium occidentale L.) apple juice's clarification process by using cassava and rice starch}

Particles suspended in solution are subject to a number of different forces. These include: (1) Gravity, the force which separates particles according to density, with the densest suspended solids moving towards the bottom of the vessel in which they are suspended. (2) Van der Waals forces are short-range attractive forces between suspended particles. These forces tend to draw suspended particles towards each other. (3) Brownian forces, dependent on temperature, impart motion to colloidal particles through collision of particles and molecules of the suspending medium. Electrostatic repulsion between charged particles tends to keep the particles apart, though shearing has an opposite effect (Doherty \& Rackemann, 2009). Coagulation of the suspended particles occurs when the forces of attraction exceed the forces of repulsion. However, the major physical reaction that occurs during clarification is the enhanced flocculation of micro-particles by the addition of an anionic copolymer flocculant. Therefore, the efficiency of bridging is a function of several physicochemical parameters, including the molecular weight of the polymer, the charge density of the polymer, the concentration of the polymer, the size and charge of the juice particles, the juice $\mathrm{pH}$ and juice temperature. In addition, the speed of flocculation is directly proportional to the velocity gradient in the solution and it is known that the type, speed and duration of agitation have a marked effect on floc structure (Peng \& Williams, 1993). The suspended particles in juice generally carry a negative charge. For coagulation of the particles to take place, the overall charge on the particles has to be neutralised to near zero charge. The mechanism of separation of tannin from the cashew apple juice is different for different clarifiers and may explain the variations observed during the clarification of cashew apple juice using cassava and rice's starch for juice clarity and tannin level. Several authors found that condensed tannins could bind starch and polysaccharides (Davis \& Hoseney, 1979; Rahman \& Richards, 1988; Le Bourvellec et al. 2012). The interactions are mostly non-covalent, hydrophobic interactions, which are governed by the molecular weight, solubility, size and conformational flexibility of phenolic compounds, proteins and starch (Belitz \& Grosch, 1999; Dlamini, 2002). Barros et al. (2012) suggested that low molecular weight polyphenols and the proanthocyanidins interact with starch via different mechanisms and indicated that oligomeric and polymeric tannins are most strongly involved in tanninstarch interactions. Thus, like proteins, starch may be interacting with the proanthocyanidins through hydrogen bonding (Hagerman \& Butler 1981; Butler et al., 1984) as well as hydrophobic interactions. Furthermore, the organic compounds available in the natural starch grains may interfere negatively with the flocculation process (Jayalekshmy \& John, 2004). Fannon et al. (1992) demonstrated that maize starch (and other cereal starches) contains large surface pores (up to $1 \mu \mathrm{m}$ diameter) which are likely sites for polyphenol adsorption into the intact granule. The larger tannin molecules are more likely to be physically trapped within the pores and thus become 'unextractable' compared to the smaller polyphenols. Additionally, hydrogen bonding is likely to increase the stability of the polyphenols within the starch granule. Previous research has demonstrated that $40-60 \%$ of condensed tannins are adsorbed on raw starches and this adsorption was dependent on the starch surface area with higher surface area having the highest condensed tannins adsorbed (Davis \& Hoseney 1979). Le Bourvellec et al. (2005) showed that due to presence of pores containing amylose chains on raw starch granules, condensed tannins would not only be adsorbed on the starch surface but could interact with amylose forming inclusion complexes. The grains of rice starch have a small size, as that of fatty globules, which brings a particular texture to the rice starch gel (Champagne, 1996; Vickery \& Rogers, 2002) while the granules of cassava's starch have a size much large. The relatively small size of the rice starch grains could offer a large surface of contacts to allow adsorption of more tannin molecules to the starch surface. In addition, when the starch grains are heated in the presence of excess water, water penetrates in the grains and involves a swelling of them. When the heating is prolonged, the amorphous amylose made soluble in the medium (Zhou et al., 2002). For the clarification, the rice and cassava starches were made soluble in water at $60^{\circ} \mathrm{C}$ (temperature of swelling and beginning of dispersion of starch grain).During the swelling of the starch grain, the amorphous amylose is continually made soluble in the medium. The starch paste obtained is composed of grains inflated that constitute the dispersed phase and, in certain cases, of made soluble macromolecules (mainly amylose) which constitute the thick phase. Because of the small size of rice starch grains, after swelling at $60^{\circ} \mathrm{C}$, these grains would have released more molecules of amorphous amylose in the solution than cassava's starch grains which sizes is relatively made soluble at the same temperature. 


\section{Dedehou et al. J. Appl. Biosci. Optimization of cashew (Anacardium occidentale L.) apple juice's clarification process by using cassava and rice starch}

The larger molecular weight proanthocyanidins provide more hydroxyl groups for hydrogen bonding, and contain more hydrophobic domains that would promote stronger interactions with gelatinized starch. (Barros et al., 2012). Jayalekshmy \& John (2004) showed that the efficiency with which different types of starch remove tannins from the juice might vary depending on the size and arrangement of amylose and amylopectin chains. Proanthocyanidins interacted more strongly with amylose compared to amylopectin. Indeed, the physical conformation of the polymeric proanthocyanidins provides more hydrophobic sites than possible with the monomeric polyphenols, while the linear nature of amylose makes its hydrophobic core more accessible in solution compared to amylopectin. While amylopectin side chains not involved in double helix structure also provide limited hydrophobic sites, steric hindrance would likely interfere with its ability to efficiently interact with the polymeric tannins. A portion of unextractable polymeric proanthocyanidins might be physically trapped within the bulky amylopectin matrix without necessarily chemically interacting with the starch. In addition, steric hindrance would be less for the monomeric polyphenols, which bound similarly to amylose and amylopectin (Barros et al., 2012).

Optimization of the parameters of clarification: The target values of the clarified juices with cassava and rice starch were selected to minimize the tannins content and to maximize the clarity. Thus, the tannins content was minimized to $66 \mathrm{mg} \mathrm{Eq}$ Catechin/100ml for cassava starch and $80 \mathrm{mg}$ Eq Catechin $/ 100 \mathrm{ml}$ for rice starch and clarity was maximized to $95 \%$. For these target values, the optimal combinations of the parameters of cashew apple juice clarification were established as indicates in table 4.

Table 4: Optimal combination of parameters for cashew apple juice clarification by using cassava and rice starch

\begin{tabular}{l|c|c|c}
\hline Starch from & Dose (ml// of juice) & Time (minutes) & Global desirability \\
\hline Cassava & 6.2 & 300 & 0.74 \\
Rice & 10 & 193 & 1 \\
\hline
\end{tabular}

The experimental responses, measured for tannins content and clarity approach the predicted responses by the model with a desirability varying between 0.81 and 0.99 (Table 5). A test of Student, to $95 \%$ of degree of confidence, indicated that there is no significant difference between the experimental responses and the values predicted by the model.

Table 5: Predicted and experimental values

\begin{tabular}{|c|c|c|c|c|}
\hline \multirow[t]{2}{*}{ Starch } & \multirow[t]{2}{*}{ Variables } & \multicolumn{2}{|c|}{ Optimum responses } & \multirow[t]{2}{*}{ Desirability (\%) } \\
\hline & & Predicted & Experimental & \\
\hline Cassava & $\begin{array}{c}\text { Tannins }(\mathrm{mg} \mathrm{Eq} \\
\text { Catechin/100 ml) } \\
\text { Clarity }(\% \mathrm{~T})\end{array}$ & $\begin{array}{c}66 \\
92.7\end{array}$ & $\begin{array}{l}67.01 \\
93.75\end{array}$ & $\begin{array}{c}1 \\
0.55\end{array}$ \\
\hline Rice & $\begin{array}{c}\text { Tannins (mg Eq } \\
\text { Catechin/100 m)I } \\
\text { Clarity }(\% \mathrm{~T})\end{array}$ & $\begin{array}{c}81.34 \\
95\end{array}$ & $\begin{array}{l}81.72 \\
94.8\end{array}$ & $\begin{array}{l}1 \\
1\end{array}$ \\
\hline
\end{tabular}

Cassava starch at $6.2 \mathrm{ml} / /$ for 300 minutes decreased the tannins at $34.2 \%$ with visual clarity of $93.75 \%$. While rice starch at $10 \mathrm{ml} / \mathrm{l}$ for 193 minutes decreased the tannins at $42.14 \%$ with visual clarity of $94.8 \%$. The clarifying agent, sago at a concentration of $2 \mathrm{~g} / \mathrm{L}$, decreased the tannins at $42.85 \%$ with visual clarity of $94 \%$. The same clarifying agent with the same concentration along with sterile filtration decreased the tannins at $41.75 \%$ with improved visual clarity of $96 \%$
(Talasila et al., 2011). 'Sago' (a natural commercial starch preparation) is an efficient clarifying agent. Tannins content of the juice clarified with starch was significantly higher than that of sago, PVP and gelatine (Jayalekshmy \& John, 2004). The clarification methods of cashew apple juices using tannase or gelatine was showed that juices treated with tannase decreases in total tannins, hydrolysable tannins, proanthocyanidins and turbidity of $46,88,2$ and $88 \%$, respectively, 
compared with $39,50,32$ and $94 \%$ for those treated with gelatine. Therefore, treatment with tannase compared with gelatine application, was more efficient at reducing hydrolysable tannins but less efficient at reducing proanthocyanidin levels in the juices. No visual differences were observed for the juices clarified by the two methods (Couri et al., 2003). The effects of clarification with gelatine, PVP or the adsorbent resin XAD-16, singly or in combination, on composition and quality of the juice showed that treatment with gelatine alone (at a concentration of $2.7-3.0 \mathrm{~g} / /$ at $20^{\circ} \mathrm{C}$ ) resulted in good clarification, and eliminated approximately $94 \%$ of the tannins. The two resins gave the poorest elimination of tannins (24\% for PVPP and

\section{CONCLUSION}

In the present research, response surface methodology with CCD is successfully used to optimize the cashew apple juice using cassava and rice starch. In the optimal conditions, cassava and rice starch preparation, are an efficient clarifying agent for cashew apple juice. Under these conditions, experiment and predicted responses were not significantly different. Cassava and

\section{ACKNOWLEDGEMENTS}

The authors are thankful to the University of AbomeyCalavi through the project Biodiversity and valorization

\section{REFERENCES}

Abreu FAP, Carvajal AMP, Dornier M, Reynes M, 2005. Evaluation de l'interêt de la microfiltration tangentielle sur membrane pour la production de jus de pomme de cajou (Anacardium occidentale, L.) Fruits 60 (1): 33-40.

ADRAO, 2003. NERICA en plein essor: un symbole d'espoir pour les riziculteurs africains. Abidjan, Côte d'lvoire, 2 p., http: // www.warda.org (le 03 juillet 2011).

Barros FAR, 2012. Sorghum tannins: interaction with starch and its effects on in vitro starch digestibility Ph.D. dissertation. Texas A \& M University, College Station, TX.

Bhat MK, 2000. Cellulases and related enzymes in biotechnology. Biotechnology Advances 18: 355-383.

Belitz HD, Grosch W, 1999. Food Chemistry, 2nd ed.; Springer: Berlin, Germany.

Benitez El, Lozano JE, 2007. Effect of gelatine on apple juice turbidity. Latin American Applied Research 37: 261-266.
$4.3 \%$ for XAD-16). Treatment with gelatine followed by adsorbent resins gave a clear, stable juice with no astringency and with a pleasant taste. Tannin and protein contents were reduced by approximately $99 \%$. These clarification treatments resulted in losses of nutrients, especially ascorbic acid (Quoc et al., 1999). Clarification of in natural cashew pulp and hydrolyzed pulp using the processes of microfiltration and ultrafiltration gave $96 \%$ reduction of condensed tannins and an increase in the luminosity of the clarified juice (Castro et al., 2007). Abreu et al. (2005) obtained 96\% reduction of condensed tannins in clarified juice with ceramic membranes.

rice starch preparation used in this study are an efficient and economic natural product to remove cashew apple tannin locally available in developing countries. These results come to solve problem of the non-control by the producers of the time and the dose of the clarifying agent (starch) necessary for a good elimination of the tannins.

of cashew products in Benin (PROANAC) for providing the funds to investigate this research.

Buléon A, Colonna P, Leloup V, 1990. Les amidons et leurs dérivés dans les industries des céréales. Actualités des industries alimentaires et agroindustrielles; Institut National de la Recherche Agronomique, Nante - France, 6: 515-532.

Broadhurst RB, and Jones WT, 1978. Analysis of condensed tannins using acidified vanillin. Journal of Science Food and Agriculture 29: 788-794.

Castro TR, de Abreu FAP, Carioca JOB, 2007. Using membrane separation processes to obtain clarified cashew apple juice. Revista Ciência Agronômica 38 (2): 164-168.

Champagne ET, 1996. Rice starch composition and characteristics. Cereal Foods World 41: 833838.

Cormier R, 2008. Clarification of Cashew Apple Juice and Commercial Applications. Oxfam Quebec, Benin, West Africa p. 1-9.

Couri S, Ferreira de Menezes L, Saavedra Pinto GA, Souza MLM, Pereira Freitas S, 2003. Comparison of the cashew apple (Anacardium 


\section{Dedehou et al. J. Appl. Biosci. Optimization of cashew (Anacardium occidentale L.) apple juice's}

clarification process by using cassava and rice starch

occidentale L.) juice clarification with tannase and gelatine. Boletim do Centro de Pesquisa e Processamento de Alimentos 20 (1): 41-54.

Davis $A B$ and Hoseney RC, 1979. Grain sorghum condensed tannins. Isolation, estimation and selective adsorption by starch. Cereal Chemistry 56: 310-314.

Dèdéhou ESCA, Dossou J, Soumanou MM, 2015. Etude diagnostique des technologies de transformation de la pomme de cajou en jus au Bénin. Int. J. Biol. Chem. Sci 9(1): 371-387.

Dlamini NR, 2007. Effect of sorghum type and processing on the antioxidant properties of sorghum [Sorghum bicolor (L.) Moench] based foods. Ph.D. Thesis, Texas A \& M University, College Station, TX, USA.

Doherty WOS. and Rackemann DW, 2009. Some aspects of calcium phosphate chemistry in sugarcane clarification. International Sugar Journal, 111(1327): 448-455.

Fannon JE, Hauber RJ, Bemiller JN, 1992. Surface pores of starch granules. Cereal Chemistry 69: 284-288.

Glèlè EKA, Adékambi SA, Agli CK, Tamegnon BA, Adégbolo PY, 2008. Impact de l'adoption des variétés améliorées de manioc au Bénin. Rapport d'activité PAPA/INRAB.

Hagerman AN, Butler LG, 1978. Protein precipitation method for the quantitative determination of tannins. Journal of Agricultural and Food Chemistry 26: 809- 812.

Jayalekshmy VG, and John PS, 2004. Sago' - a natural product for cashew apple juice clarification. Journal of Tropical Agriculture 42: 67-68.

Kayodé AAP, Hounhouigan JD, Stomp TJ, Smulders MJ, 2006. Diversity and food quality properties of farmer's varieties of sorghum from Benin. Journal of Science Food and Agriculture 86: 1032-1039.

Kilara A, and Van Buren J, 1989. Clarification of apple juice. In Processed Apple Products. D.L. Downing (Ed.), Van Nostrand Reinhold, New York.

Le Bourvellec CL, Bouchet B, Renard CMGC, 2005. Non-covalent interaction between procyanidins and apple cell wall material. Part III: Study on model polysaccharides. Biochim. Biophys. Acta 1725: 10-18.

Le Bourvellec C, Renard CMGC, 2012. Interactions between Polyphenols and Macromolecules: Quantification Methods and Mechanisms.
Critical Review of Food Sciences and Nutrition 52: 213-248.

Michodjehoun-Mestres L, Souquet JM, Fulcrand $\mathrm{H}$, Bouchut C, Reynesa M, Brillouet JM, 2009. Monomeric phenols of cashew apple (Anacardium occidentale L.). Food Chemistry 112: 851-857.

Peng SJ, and Williams RA, 1993. Control and optimization of mineral flocculation and transport processes using on-line particle size analysis. Minerals Engineering 6: 133-153.

Quoc AL, Fustier P, Couture R, Castaigne F, Makhlouf J, 1999. Effect of various clarification agents on tannin removal, chemical composition and stability of cashew juice. Sciences des Aliments 18 (4): 375-391.

Rahman MD, Richards GN, 1988. Interactions of starch and other polysaccharides with condensed tannins in hot water extracts of ponderosa pine bark. J. Wood Chem. Technol 8: 111-120.

Siebert KJ, Troukhanova NV, Lynn PY, 1996. Nature of polyphenol-protein interactions Journal of Agricultural and Food Chemistry 44: 80-85.

Talasila U, Vechalapua RR, Shaik KB, 2011. Preservation and shelf life extension of cashew apple juice. Internet Journal of Food Safety 13: 275-280.

Talasila U, Vechalapu RR, Shaik KB, 2012. Clarification, Preservation and Shelf Life Evaluation of Cashew Apple Juice. Food Science Biotechnology 21(3): 709-714.

Van Buren JP, Robinson WB, 1969. Formation of complexes between protein and tannic acid. Journal of Agricultural and Food Chemistry 17(4): 772-777.

Vickery AP, and Rogers RW, 2002. The use of fat replacers in low-fat pepperoni. Journal of Muscle Foods 13: 205-222.

Wu Y, Chen Z, Li X, Li M, 2009. Effect of tea polyphenols on the retrogradation of rice starch. Food Research . International 42: 221225.

Zepka LQ, Borsarelli CD, Silva MAAP, Mercadante AZ, 2009. Thermal degradation kinetics of carotenoids in a cashew apple juice model and its impact on the system colour. Journal of Agricultural and Food Chemistry 57(17): 78417845.

Zhou Z, Robards K, Helliwell S, Blanchard C, 2002. Review-Composition and functional properties 
Dedehou et al. J. Appl. Biosci. Optimization of cashew (Anacardium occidentale L.) apple juice's clarification process by using cassava and rice starch

of rice. International Journal of Food Science and Technology 37: 849-868.

Zoecklein B,1988. Bentonite fining of juice and wine. Department of Horticulture. Virginia
Polytechnic Institute \& State University. Publication 463-014.

Zoffoun A, Aïhou K, AKakpo C, 2001. Test variétal du clone de manioc RB 89509. Actes de l'Atelier Scientifique Niaouli 12-13 Décembre. 